\title{
ESTUDO DA BIOCONVERSÃO DE RESÍDUOS AGROINDUSTRIAIS LIGNOCELULÓSICOS POR LENTINULA EDODES: PRODUÇÃO E CARACTERIZAÇÃO DE PROTEÍNA UNICELULAR
}

\section{STUDY OF THE LIGNOCELULOSICS AGRO-INDUSTRIAL RESIDUES BIOCONVERTION FOR LENTINULA EDODES: UNICELLULAR PROTEIN PRODUCTION AND CHARACTERIZATION}

\author{
Patrícia Fernanda Reffatti ${ }^{1}$; Caroline Mariana de Aguiar $^{2}$ Marcio Barreto-Rodrigues $^{3}$ \\ ${ }^{1}$ Acadêmica do curso de Tecnologia em Química Industrial - UTFPR - Pato Branco - PR - Brasil. \\ preffatti@gmail.com \\ ${ }^{2}$ Tecnólogo em Química Industrial - UTFPR - Pato Branco - PR - Brasil. \\ caroline de aguiar@yahoo.com.br \\ ${ }^{3}$ Prof. Dr. Márcio Barreto-Rodrigues - UTFPR - Pato Branco - PR - Brasil. \\ marcio-barreto@hotmail.com
}

\begin{abstract}
Resumo
$O$ presente trabalho fundamenta-se em estudo da bioconversão de residuos agroindustriais lignocelulósicos de um efluente oriundo de processo de beneficiamento de madeira, com o objetivo principal de produção de proteína unicelular. O trabalho utilizou planejamento fatorial de experimentos $2^{3}$, considerando como fatores experimentais o conteúdo de nitrogênio, co-substrato (glicose) e tempo. A interpretação das respostas consideradas, indicou que a melhor condição para a produção de biomassa protéica é aquela que utilizou o próprio efluente como fonte de nitrogênio, e 30 dias de tratamento. Nestas condições, conduziu-se a uma otimização do bioprocesso em bioreator, com controle de temperatura, $\mathrm{pH}$ e alimentação, tendo sido possível a obtenção de um rendimento biológico de aproximadamente $8 \mathrm{~g} / \mathrm{L}$ de biomassa, com teor protéico da ordem de $17 \%$. Estes resultados demonstraram o grande potencial do fungo Lentinula Edodes, para a utilização dos componentes do efluente para a produção de biomassa protéica.
\end{abstract}

Palavras-chave: Resíduos agro-industriais lignocelulósicos; bioconversão; proteína unicelular; Lentinula edodes.

\section{Introdução}

Os microorganimos têm sido utilizado em diversos alimentos a séculos, isto deve-se a propriedade que possuem de produzir enzimas e substâncias utilizadas na preparação de grande parte dos alimentos consumidos pelo homen (FRAZIER; WESTHOFF,1978; MONTEIRO, 1986).

Atualmente o foco para os microorganismos está voltada na produção de biomassa proteica ou unicelular, a qual refere-se ao crescimento primário dos microorganismos com posterior 
recolhimento das células microbianas. Essas células são caracterizadas principalmente pelo seu teor alto de proteina, porém a biomassa contém também carboidratos, lipídios, vitaminas, minerais, e nitrogênio não proteico (LITCHEFIELD, 1983).

De acordo com Pelczar e Chan (1981), o que atrai os pesquizadores para a produção de proteina unicelular é a capacidade dos microorganismos crescerem rapidamente, com grande rendimento dessas células. Outra vantagem notável é a possibilidade de utilização de resíduos agroindustriais ou subprodutos lignocelulósicos como substrato para o crescimento destes (Frazier e Westhoff (1978); Dabbah, 1970: Batt e Sinskey, 1984: Camargo, 1984).

A produção de proteina microbiana a partir de residuos industriais/agroindustriais já vêm sendo obtido por WILSON E THAYER (1982), BAJPAI e BAJPAI (1986) a partir de hidrolisado de materiais celulósicos, com a levedura Candida utilis o qual obteve-se biomassa com $66 \%$ e $45 \%$ de proteina, respectivamente.

Os residuos lignocelulósicos apresentam em sua estrutura principalmente celulose, hemicelulose e a lignina, cujas apresentam grande dificuldade em relação a sua degradação, dificultando no caso no processamento da madeira, o processo de tratamento desses resíduos (SCRIBAN, 1985). Por esse motivo a procura por processos alternativos para reutilizar esses residuos lignocelulósicos tem levado aos fungos comestiveis, particularmente aos da espécie que atacam a madeira, degradando a fração da lignina do complexo e deixando os resíduos biotranformados, sem problemas toxicológicos. Exemplos de fungos lignocelulósicos são os fungos Volvariella sp, Lentinula Edodes e Pleurotus sp (NICOLINI et al., 1993).

O Lentinus edodes, fungo lignolítico, produz uma série de enzimas hidrolíticas e oxidativas, envolvidas no processo de degradação dos principais componentes de materiais lignocelulósicos. A otimização da produção e a eficiência biológica dos cogumelos conduz a uma mais efetiva degradação dos referidos polímeros e a uma maior valorização dos resíduos lignocelulósicos.A utilização de diversos tipos de substratos pelo fungo depende da sua capacidade de secretar celulases, hemicelulases e ligninases, liberando nutrientes para seu crescimento. (Platt et al., 1981).

\section{Materiais e métodos}

O microorganismo estudado neste trabalho foi o fungo lignolítico Lentinula edodes UEC 2019 da coleção microbiana do Departamento de Biotecnologia Industrial da Faculdade de Engenharia Química de Lorena/SP. O substrato utilizado foi cedido por uma agroindústria de beneficiamento de madeira da região sudoeste do Paraná. As análises foram realizadas no laboratório de Química e de Alimentos da UTFPR, unidade de Pato Branco. 


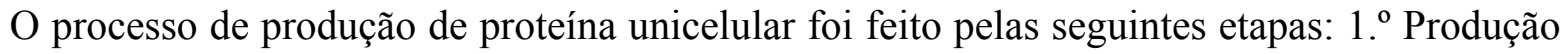
de proteína unicelular em Shaker Orbital; 2. ${ }^{\circ}$ Produção de proteína unicelular em bioreator de bancada; $3 .^{\circ}$ Caracterização da biomassa produzida.

\subsection{Produção de proteína unicelular em Shaker Orbital}

A produção de proteína unicelular em Shaker foi realizada inoculando-se os microoganismos em meio contendo meio efluente lignocelulósico bruto e deixando-os sob rotação constante (100 rpm). Através desse processo pode-se avaliar a melhor condição de desenvolvimento do fungo para posterior otimização de produção de proteína unicelular em bioreator. Realizou-se um planejamento fatorial $2^{3}$ considerando os fatores fonte de carbono (glicose), fonte de nitrogênio (sulfato de amônio / próprio efluente) e tempo. Os níveis e variáveis deste planejamento estão apresentados na tabela 1 .

Tabela 1- Planejamento Fatorial $2^{3}$

\begin{tabular}{|l|l|l|l|}
\hline Níveis & $(-)$ & $(0)$ & $(+)$ \\
Fatores & & & \\
\hline Glicose (mg/L) & 1000 & 40000 & 75000 \\
Fonte de Nitrogênio (mg/L) & 100 & 300 & 500 \\
\hline Tempo (dias) & 10 & 20 & 30 \\
\hline
\end{tabular}

Nota: Nível ( - ) de nitrogênio refere-se ao conteúdo presente no próprio efluente.

Após concluido esse periodo de incubação e crescimento biológico, realizou-se a separação da biomassa obtida do meio inoculante. A biomassa então foi pesado para a obtenção do valor seco e rendimento.

\subsection{Produção de proteína unicelular em bioreator de bancada}

As condições que se mostraram ótimas no Shaker orbital foram reproduzidas em bioreator BIOSTAT ${ }^{\circledR}$ B da B. Braun Biotech International, pertencente ao laboratório de Apoio a Pesquisa da Universidade Tecnológica Federal do Paraná - Unidade Sudoeste, Campus de Pato Branco, onde consegui-se controlar a monitorar condições como: temperatura, $\mathrm{pH}$ e rotação. Retirou-se a proteína unicelular produzida e realizou-se sua separação, lavagem com água a $60^{\circ} \mathrm{C}$ e secagem a $60^{\circ} \mathrm{C}$ por dois dias e, posteriormente, sua caracterização. 


\subsection{Caracterização da biomassa produzida (proteína unicelular)}

A biomassa produzida foi caracterizada quanto aos seguintes parâmetros: umidade (método gravimétrico), cinzas (método gravimétrico), proteínas (Kjeldahl), lipídeos (Soxlet) e fibra (gravimétrico).

\section{Resultados e discussão}

As discussões dos resultados obtidos, apresentados a seguir, referem-se aos estudos da produção e caracterização de proteina unicelular obtida.

\subsection{Estudo da produção de proteína unicelular em Shaker Orbital}

Com a interação dos niveis e dos fatores gerados pelo planejamento fatorial $2^{3}$, obteve-se a matriz de experimentos, na qual foram previstos oito pontos experimentais e duas replicatas de ponto central.

As amostras foram retiradas do Shaker após 10, 20 e 30 dias. A biomassa produzida foi separada do efluente e pesada. Após a pesagem da biomassa em placas de petri secas, colocou-se em estufa a $40^{\circ} \mathrm{C}$ para ser realizada a secagem. Após este, as placa contendo a biomassa, foram pesadas novamente. Desta forma obteve-se os rendimento conforme tabela 2.

Tabela 2 - Rendimento da biomassa protéica total produzida em Shaker Orbital

\begin{tabular}{|c|c|c|c|}
\hline Ensaios & Peso seco $(\mathrm{g})$ & Rendimento g/l & \% Biomassa \\
\hline 1 & 49,6983 & 0,468 & 1,619 \\
\hline 2 & 48,1097 & 2,240 & 2,077 \\
\hline 3 & 50,0075 & 7,893 & 5,727 \\
\hline 4 & 49,6410 & 4,575 & 0,719 \\
\hline 5 & 39,5737 & 0,525 & 6,689 \\
\hline 6 & 50,2830 & 5,545 & 1,679 \\
\hline 7 & 38,2444 & 0,535 & 5,547 \\
\hline 8 & 42,1195 & 5,708 & 7,500 \\
\hline 9 & 55,2671 & 7,677 & 4,001 \\
\hline 10 & 50,8599 & 4,120 & \\
\hline
\end{tabular}

Através da interpretação da tabela 2 foi possível observar, isoladamente, que as condições experimentais que levam ao maior rendimento em termos de biomassa é a número três, seis, oito e 
nove.

As figuras 1 e 2 elucidam a interpretação da resposta biomassa em relação aos três fatores (glicose, nitrogênio e tempo). As figuras foram criadas através do programa de estatística STATGRAF.

Figura 1- Interpretação Geométrica dos fatores em relação à \% biomassa.

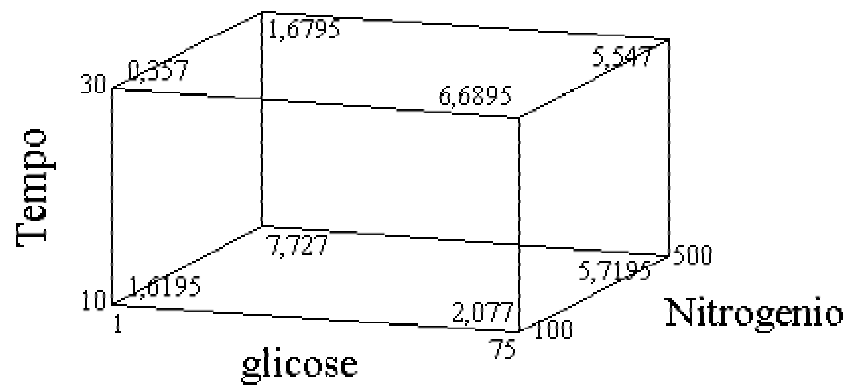

Pode-se observar a partir da figura 1 que um bom rendimento da biomassa apresenta-se no ponto onde a concentração de glicose e tempo é menor e de nitrogênio é maior (rendimento de 7,7 $\%$ ). Entretanto, considerou-se também interessante o ponto experimental relativo aos níveis superiores de tempo e glicose e onde a concentração de nitrogênio foi menor (rendimento de 6,6895\%). Apesar de esta condição o rendimento da biomassa ter sido menor, as reduções de fenóis e cor do efluente foram comparativamente superiores, ou seja, o conjunto avaliado apresenta maior eficiência ou resultado quando o microorganismo encontra-se sob essas condições. Como anteriormente comentado, este comportamento pode estar relacionado no fato da menor concentração de nitrogênio favorecer uma condição lignolítica, onde a atividade de enzimas oxidativas é maior, promovendo a quebra dos grupos cromóforos da lignina oxidando e mineralizando os compostos fenólicos e fragmentos de lignina remanescentes.

A superfície de resposta da figura 2 mostra com mais clareza e interdependência entre os fatores experimentais nitrogênio e teor de glicose para a produção de biomassa.

Figura 2- Superfície de resposta, considerando os fatores tempo, glicose e nitrogênio.

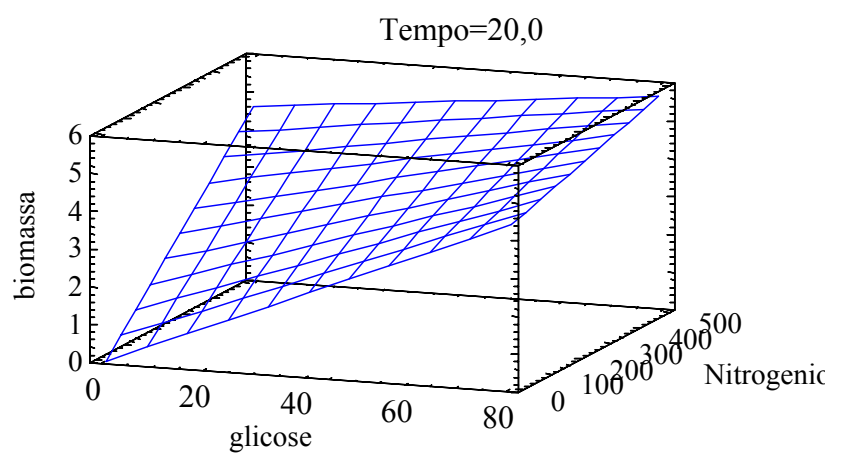


As respostas do estudo mutilvariado indicaram, portanto, que as condições que levaram a maior produção de biomassa protéica $(\approx 7 \%$ ) foram: nível $(-)$ de nitrogênio (ou seja, utilizando os componentes do próprio efluente como fonte de nitrogênio); nível $(+)$ de glicose e nível $(+)$ de tempo.

\subsection{Produção de proteína unicelular em Bioreator}

As condições do planejamento fatorial que se mostraram ótimas no Shaker Orbital apresentadas no topico anterior, foram mantidas para o trabalho em bioreator, no qual obteve-se a bioconversão de 4 litros de efluente lignocelulósico em aproximadamente $8 \mathrm{~g} / \mathrm{L}$ de biomassa.

\subsection{Caracterização da proteína unicelular obtida pelo bioreator, através do efluente lignocelulósico}

Após a retirada do bioreator, a proteína unicelular foi caracterizada, obtendo os seguintes resultados: $17.250 \%$ de proteína, $79.454 \%$ de umidade, $3.307 \%$ de cinzas, $3.710 \%$ de fibras, $0.903 \%$ de gordura, com rendimento de biomassa por litro de efluente de aproximadamente $8 \mathrm{~g} / \mathrm{L}$.

A literatura especializada não mantém muitos trabalhos acerca do rendimento de biomassa a partir deste tipo de efluente com o mesmo microorganismo. Entretanto, para efeito de comparação, Almeida Lima e colaboradores (2001) relataram um rendimento de $17 \mathrm{~g} / \mathrm{L}$ de micélio (biomassa fúngica) para conversão de licor sulfítico utilizando o microorganismo Paecilomyces variotti.

Considerando que alguns autores relatam teores protéicos que variam de $15-60 \%$, consideramos o valor alcançado (17\%), relativamente baixo. Por outro lado, os próprios pesquisadores afirmam que este índice depende principalmente do tipo de microorganismo e da natureza do substrato utilizado. Neste sentido, considerando que se trata de biomassa protéica de Lentinula edodes consideramos que teor protéico alcançado colabora com aqueles reportados para corpos de frutificação e biomassa miceliares deste microorganismo (Beux, 1998; Da Silva, 1981). De acordo com Przybylowicz (1990), o teor de proteína para corpos de frutificação de Lentinus edodes é de 10 a $17 \%$. 


\title{
4. Conclusão
}

O bioprocesso estudado produziu micélio fúngico de Lentinula edodes com teor protéico de 17\%. Portanto, a biomassa produzida apresentou composição nutricional significante, condizendo com os valores apresentados por vários autores podendo, assim, ser utilizada em rações para animais, por exemplo, como suplemento nutricional.

\begin{abstract}
The objective of the experiment was the bioconversion of lignocelulósics agro-industrial residues of ann effluent of wood improvement process, the main objective is unicellular protein production. The work used factorial planning of experiments $2^{3}$, considering as experimental factors the content of nitrogen, co-substratum (glucose) and time. The interpretation of the considered answers, indicated that the best condition for the production of unicellular protein is the one the nitrogen source the proper effluent as, and 30 days of treatment. In these conditions, it was conducted approximately an reproduction of bioprocesses in bioreactor, with control of temperature, $\mathrm{pH}$ and feeding, having been possible the attainment of a biological income of $8 \mathrm{~g} / \mathrm{L}$ of biomass, with tenor of the protein aproximately $17 \%$. These results had demonstrated the great potential of Lentinula Edodes, for the use of the components of the effluent one for the production of biomass of protein.
\end{abstract}

Key-words: Lignocelulósicos agro-industrial residues; unicellular protein; Lentinula edodes.

\section{Referências}

BAJPAI, P. \& BAJPAI, P. K. Cultivation of yeast from the prehydrolisate from rayon pulp mill. Enzyme and Microbial Technology: 610-612, 1986.

BAJPAI, P. \& BAJPAI, P. K. Repeated fed batch fermentation for single cell protein production form prehydrolysate of a pulp mill. Enzyme and Microbial Technology: (10) 280-283, 1988.

BAJPAI, P. \& BAJPAI, P. K. Single cell protein production from rayon pulp mill waste by Paecilomyces variotii. Journal of Fermentation Technology, 65 (3): 349-351, 1987.

BEUX, Márcia. Aproveitamentos de resíduos agroindustriais do Paraná para produção de cogumelos comestíveis do gênero Pleorotus sp.; UFPR, Curitiba, 1998.

CAMARGO, R. et all. Tecnologia dos produtos agropecuários - Alimentos. São Paulo, Nobel, 1984. cap.15, p.285297.

DABBAH, R. Protein from microorganisms. Food Technology, 24: 659- 666, 1970.

BATT, C.A. \& SINSKEY, A. J. Use of biotechnology in the production of single cell protein. Food Technology, 38 (2): 108-111, 1984.

FRAZIER, W. C.; WESTHOFF, D.C. Microbiologia de los Alimentos. Editora Acribia S.A, 1978

LITCHFIELD, J. H. Single cell protein. Science, 219: 740-746, 1983.

NICOLINI, L., VOLPE, C., PEZZOTTI, A. et al. Changes in in-vitro digestibility of orange peels and distillery grape stalks after solid-state fermentation by higher fungi. Bioresource Technology, v.45, p.17-20, 1993. 
PLATT, M. W.; HADAR, Y.; HENIS, Y.; CHET, I. Lignocelluloses degradation of during growth of the Pleurotus sp. "Florida" on cotton straw. European Journal Applied Microbiology Biotechnology, Rehovot, v. 13, p. 194-201, 1981.

PELCZAR, M.; Reid, R.; Chan, E. C. S. Microbiologia. Vol. I; Editora McGraw - Hill, 1980.

PELCZAR, M.; Reid, R.; Chan, E. C. S. Microbiologia. Vol. II; Editora McGraw - Hill, 1981.

Scriban, R.; Biotecnologia. Editora Manole, 1985.

WILSON, D. U. \& THAYER, D. W. Growth of Cândida utilitis and Pseudomonas JM 127 in mixed culture treated and untreated mesquite. Devopments in industrial microbiology, 23: 337-349, 1982.

\section{Primeiro autor:}

Nome completo: Patrícia Fernanda Reffatti

Filiação institucional: UTFPR - Campus Sudoeste - PR

Função ou cargo ocupado: Acadêmica do $8^{\circ}$ período do curso de Tecnologia em Química Industrial - UTFPR - Campus Sudoeste - PR - Brasil.

Endereço completo para correspondência (bairro, cidade, estado, país e CEP):

Rua Roberto Silveira, 847, Centro Sul - Cep: 85.660.000 - Dois Vizinhos - PR - Brasil.

Telefones para contato: 04635361666 - 04699764246.

e-mail:preffatti@gmail.com, patricia_reffatti@hotmail.com 